\title{
Research on Teaching Reform and Innovation of Computer Introduction Course Based on New Engineering
}

\author{
Jinhuan Wang \\ Intelligent Science \& Information Engineering College, Xi'an \\ Peihua University \\ Xi'an 710125, China \\ 360635476@qq.com
}

\begin{abstract}
At present, there is still a certain gap between the teaching of computer-introduction course and the current application-oriented teaching goal. This paper analyzes and discusses the problems existing in the teaching process, and proposes the teaching method reform of the computer introduction course based on the new engineering. We reformed the design of teaching objectives, the design of teaching process, the flexible application of teaching aids and the verification method of teaching results, which better achieved the goal of matching the goal of computer introductory course teaching with the goal of applied talent training. The demand for applied talents provides an important basis and reference for the reform of applied talents curriculum. The reform satisfies the demand for applied talents in the context of new engineering, and provides an important basis and reference for the curriculum reform of applied talents.
\end{abstract}

Keywords-Teaching reform; New engineering; Computer introduction; Teaching method

\section{INTRODUCTION}

Introduction to Computer is one of the professional basic courses of computer science, which is a combination of theory and practice. The traditional teaching method is through theoretical teaching method. The knowledge of students' learning is out of line with the actual needs of the society, the students' practical ability is poor, and there is a certain gap between the skills that the enterprise requires for the employees. In order to cultivate new types of engineering talents that meet the needs of adapting to the development of the new economic speed, it is proposed to apply the teaching reform to the course, change the teaching concept, innovate the teaching mode, and reorganize the knowledge structure. Strengthening student practice training is an urgent task that needs to be solved, stimulating students' interest in learning and improving their innovation ability.

The reform of computer introduction course based on new engineering. Through the analysis and research on the current situation of computer introduction course, this paper discusses

\author{
Wei Wei \\ Intelligent Science \& Information Engineering College, Xi'an \\ Peihua University \\ Xi'an 710125, China \\ 2366844698@qq.com
}

the ability requirements of the computer introduction course under the new engineering background. We proposed a new teaching plan, and formulated a student-oriented course structure and implementation plan, and formed a new curriculum teaching model that integrates thinking, technology, methodology and practice. Therefore, a batch of innovative talents would be cultivated to meet the needs of new engineering talents and curriculum reforms required for the rapid development of the new economy. Next we mainly proceed from three aspects:

\section{TEACHING GOAL DESIGN}

The design of teaching objectives should be clear and concise, and the objectives should be unique and targeted. The achievement of the ability goals under the professional curriculum system is mainly from the following three aspects:

Practice innovation ability (by learning innovative entrepreneurship courses, practical courses): database technology, software engineering, programming, multimedia technology, social career issues and computer new technologies.

Professional skills include: familiar with the office environment, multimedia technology, data structure, software knowledge of graphic design and static website design.

Job search skills: teamwork, communication skills, ability to collect and retrieve information, self-developed learning, scientific innovation, decision making and execution. The teaching reform design mainly focuses on the following four aspects:

\section{A. Meet the basic model and basic problems of computer technology talent training}

Analyze and research the rapidly developing computer technology, computer talent training system, and individualized student groups. 


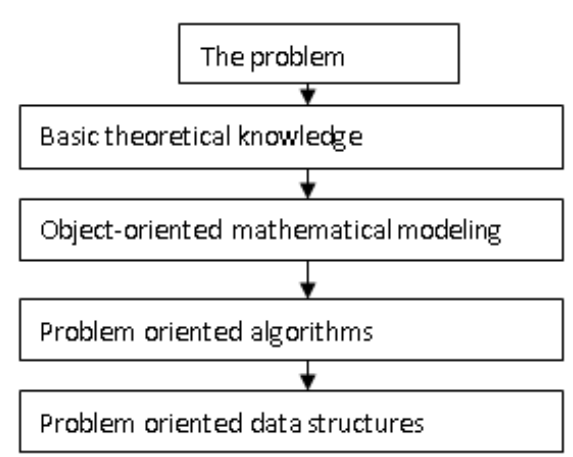

Fig. 1 Problem solving recursive graph

\section{B. Student-oriented curriculum structure and implementation plan}

Teaching materials--take solving problems as the goal, take depth as the priority and inspiration as the means; self-study materials-- extraction of classic textbooks for self-study before class; Discussion topic--teacher topics; after-school homework--based on the exercises in the textbook, covering all the learning content; programming training-give some questions around the topics.

\section{New method of curriculum construction}

Forming a new curriculum teaching method integrating thinking, technology, methodology and practice, it mainly innovates from the following five aspects:

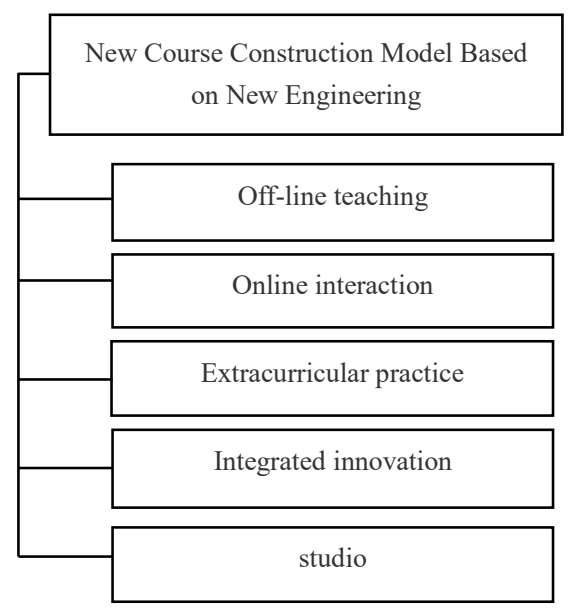

Fig. 2 A new method of computer introduction course construction based on new engineering

Offline teaching: basic concepts, thinking methods, principle technology, application cases; Online WeChat public account interactive platform: teacher-student interaction, courseware synchronization, key explanation, supplementary reading; extracurricular practice: focus on hands-on practice; Adjust the teaching content outside the textbook, pay attention to multi-export, improve the ability through competition, strive to transform the teaching content into student ability, improve students' practical ability through the exercise of students; Comprehensive innovation: improve the innovative thinking of students by participating in the college students' innovation and entrepreneurship projects, Internet + and other projects. The new management method: simulation to set up a studio (3-6 people): with captains, programmers, designers, testers and other positions, the main purpose is to cultivate students' sense of teamwork, interest and mission.

\section{Introduce online training platform}

The online training platform is a continuation and supplement of the MOOC platform. It mainly provides an online training environment for computer courses. The platform includes: course system, question database, online practice, case library, and data competition. Including the model of online training platform; the difficulties and key points of the connection between enterprise resources and college courses; the structure and function design of online training platform; the research on the design and implementation of curriculum implementation plan.

Through online education, the seamless connection between college students and enterprise skills learning is a new form of school-enterprise cooperation under the age of Internet + . It can realize first-line enterprise skill courses docking colleges with low-cost, and students can learn relevant skills safely and conveniently.

\section{THE DESIGN OF TEACHING PROCESS}

The design of the teaching process is very important. The goal of good teaching needs the excellent design of effective teaching process to complete. In the design of teaching process, various teaching techniques can be effectively combined to make the teaching materials and courseware design put into full play, and appropriate expression techniques such as behavioral teaching and body language teaching can be adopted. In the design of the teaching process, it is necessary to adopt various teaching methods reasonably, and there are three teaching methods that have been proved to effectively improve the teaching quality by practice:

\section{A. The upstairs structured teaching method}

The upstairs structured teaching method is also called single-chain teaching method. The vertical task is decomposed. There is only one knowledge point in one step. The last few steps mention the previous knowledge points. The rhythm is compact, the control is strong, and the interval is paused and repeated. In other words, one step at a time, one pause at a time, repeat the knowledge point on the reentry; carry out a five-step one reentry in the rest stage, summarizing and consolidating the knowledge.

\section{B. Occam razor principle}

The idea of Occam's razor principle is to be removed if it is not necessary. This method has proven to be a very effective teaching method, which means that the efficiency of teaching is based on the acceptance rate of the students, not the amount prepared by the teacher.

\section{Deep connotation interactive teaching method}

The main idea of the deep connotation interactive teaching method is to use a large number of cases in the teaching, lock the knowledge points in the case, watch the game, provide materials, simple knowledge points, propose a question for 
group discussion, single answer, let as much as possible students participate in the discussion. And the full case, the starting case and the ending case are equal to the absorption rate.

Reorganizing the knowledge points of the course according to the needs of the project, which is no longer a mere theory, but a hands-on practice. Taking the project as the main body-integrating the subject teaching content: setting the project according to the course content, the project takes the real product as the carrier. Taking the task as the center to organize the course teaching: further subdivide the project, make a personal resume and poster; The classroom teaching with chart for class grades is driven by tasks: the content of the class is centered around the task; the goal is improving job search ability, and pay attention to the cultivation of engineering application ability. Students are the main body, and the task process is carried out by the students themselves.

According to the task analysis, plan formulation, task implementation, task evaluation, the four links take the work process through the classroom, reflecting the teaching philosophy of the teaching task.

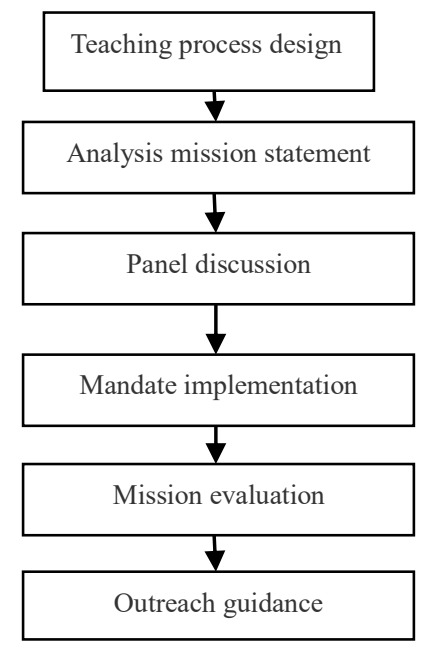

Fig. 3 Teaching process design

\section{TEACHING ACCEPTANCE METHOD}

Scholastic education and incentive acceptance are adopted to encourage students to promptly and effectively, cancel the traditional examination system, increase the process evaluation, change the mode of the "one test deciding the result", and adopt the usual homework + training program + student work $=$ course score.

\section{A. Assessment}

The whole process assessment method is used to evaluate the students' learning; according to the basic knowledge, professional ability and professional quality, the performance of one student is assessed from the aspects of usual performance, teamwork, project implementation and reporting; the usual performance accounts for $10 \%$; Teamwork accounted for $15 \%$; project implementation accounted for $60 \%$; experimental report accounted for $15 \%$.

\section{B. Introduce "Moso Teach"}

The WeChat public account interactive platform enters the classroom, the new curriculum construction method and implementation plan, the combination between offline and online.

\section{Change points rule}

If you participate in various discipline competitions and win prizes, you can exchange credits or offset the results of the subjects, which is more scientific and reasonable, and more in line with the innovation and cultivation of applied talents. If you win the provincial award and are in the top three, you can change 5 credits or offset 2 courses; if you get the top three national awards, you can also get 12 credits or offset 5 grades.

Promote the "scholarship system", "dormitory system", "squad leader system", "scholar system", "mentor system" and other related systems, as well as reward system to stimulate their motivation and enthusiasm.

Promote the "interest class" in the freshman year; the "project class" in the sophomore year; the "study class" in the third year.

\section{CONCLUSION}

Based on the analysis of the problems existing in the traditional teaching methods, this paper puts forward the reform of the computer introduction course based on the new engineering, focusing on the reform of teaching methods, including the design of teaching objectives, the design of teaching process, teaching techniques, teaching materials and courseware design, teaching acceptance, all of which have been elaborated clearly. With students as the center and based on market demand, we aim to cultivate high-quality applied talents. Practice has proved that the teaching effect has been greatly improved, and the cultivation of applied talents has been better realized, and the employment competitiveness of students has also been improved.

\section{ACKNOWLEDGMENT}

The subject of "the thirteenth Five-Year Plan" for Education Science in Shaanxi Province in 2018 is " Research on Computer Course Construction and Innovation under the Background of New Engineering - take "An Introduction to Computer Science" as an example" (No. SGH18H509). Xi'an Peihua university reform of education and teaching research project in 2018 (Project No. PHY1819). 


\section{REFERENCES}

[1] Yuan Fang, Wang Bing, Li Jimin, Zhang Ming. Reforming teaching methods- Giving play to the "five guides" of computer introduction [J]. Computer Education. 2011 (1): 95-97.

[2] Chang Rui, Jiang Liehui, He Hongqi, Song Chengjie. Talking about the cultivation of computational thinking ability in practical teaching of computer science $[\mathrm{J}]$. Computer Engineering and Science.2014.36(2):88-91.

[3] Ye Min. New Engineering - From theory to action [J]. Advanced Engineering Construction Research. 2018. No. 1. 24-32.

[4] Zhou Kaifa. Exploration of core competence and teaching method of new engineering $[\mathrm{J}]$. Chongqing Higher Education Research 2017.5.22-36.

[5] Xia Jianguo. Study on the Reform and Development of Engineering Education in Local Universities under the Background of New Engineering Construction[J]. Journal of Higher Education Research.2017, No.3.15-26.

[6] Notice of the Higher Education Department of the Ministry of Education on the research and practice of new engineering [EB/OL].(2017-02-20). 